\title{
Hybrid Transshipment Policy and Ordering Model for Multiple Periods with Customer Switching Behaviour
}

\author{
Qingren He $\mathbb{D}^{1,2}$ Ranran Shi $\mathbb{D}^{2},{ }^{2}$ and Guofeng Tang ${ }^{3}$ \\ ${ }^{1}$ School of Economics and Management, Beihang University, Beijing, China \\ ${ }^{2}$ School of Management, Guizhou University, Guiyang, Guizhou, China \\ ${ }^{3}$ School of Management Science and Engineering, Chongqing Technology and Business University, Chongqing, China
}

Correspondence should be addressed to Ranran Shi; shirr2018@gmail.com

Received 20 September 2021; Accepted 20 November 2021; Published 20 December 2021

Academic Editor: Baogui Xin

Copyright ( 92021 Qingren He et al. This is an open access article distributed under the Creative Commons Attribution License, which permits unrestricted use, distribution, and reproduction in any medium, provided the original work is properly cited.

The interaction of a hybrid transshipment policy and customer switching behaviour will exacerbate the complexity of the structure of a hybrid transshipment policy. To cope with this problem, a discrete-time dynamic programming model framework with customer switching behaviour is developed. Based on this framework, we demonstrate that the retailer can obtain more profits with a hybrid transshipment than without one. Next, the existence of a reactive and preventive transshipment policy is shown, respectively. We further analyse the structural property of the holdback policy of reactive transshipment and give the threshold of customer switching rate when always rejecting the request. Meanwhile, a dominant preventive transshipment policy is formulated by which the retailer can control the inventory regardless of the influence of the preventive transshipment policy of the other as long as the inventory is observed by developing an easy-to-implement optimal hybrid transshipment strategy. In addition, the existence of an ordering Nash equilibrium of two retailers is proven. Then, we also illustrate the existence of a transshipment area and analyse the impact of the transshipment cost and switching rate on ordering, the hybrid transshipment policy, and profit by using numerical examples. Finally, we find that the retailer is more willing to adjust inventory by ordering when there is a lower transshipment price and adjust inventory by hybrid transshipment when there is a higher transshipment price.

\section{Introduction}

A demanding variety in the categories of perishable products results in a higher uncertainty in the supply and demand for these products. Subsequently, the production of perishable products is usually too much (making these products overstocked) or too little (leading to quickly running out of their stocks). As a remedy to this problem, some retailers attempted to adopt the strategy of reactive transshipment, with an aim to establish a new paradigm, which came to be known as one of "risk pooling." However, the paradigm of reactive transshipment suffers from serious limitations when used to govern the response to customer needs. For instance, when a situation in which a product is out of stock arises, a significant delivery delay can occur due to this stockout even if the demand is ultimately met. Thus, more and more customers will impatiently give up because it takes longer times to fulfil their demands through reactive transshipment when a stockout occurs. A recently conducted survey that dealt with more than 71,000 customers found that the majority of customers are too impatient when stockouts take place. In fact, only $15 \%$ of the surveyed customers prefer a delayed purchase to no purchase at all [1]. To make matters even worse, unsatisfied customers are likely to switch to competitors when a stockout occurs. This customer switching behaviour is not uncommon [2]. According to Tierney [3], a survey by $P \& G$ finds that $50 \%$ of customers may turn to other retailers when the original retailer experiences a stockout. Verbeke and Thurilk [4] also note that $34 \%$ of the Coca-Cola customers simply switch to other stores if the store they target first has no inventory. The above survey also shows that $31 \%$ of unsatisfied customers switch to a competitor when the exact sought products are not found [1]. 
The reactive transshipment policy does not probably provide a satisfactory response for customers who are impatient with stockouts. Therefore, leading fashion designers, such as ZARA and H\&M, are trying to employ a preventive transshipment so as to avoid most of the losses incurred by the reactive transshipment $[5,6]$. Typically, transshipment can be categorized into two different transshipment policies, namely, preventive transshipments (which tries to prevent stockouts) and reactive transshipments (which avoids delivery delays when there is no shortage). Preventive transshipment refers to sending a transshipment request to another retailer to balance the inventory before customer's demand is met [7]. By contrast, reactive transshipment is employed as a reactive action after satisfying the retailer's own demand. It involves making an emergency-supply request to be forwarded to another location that possesses surplus inventory. Therefore, a preventive transshipment provides the retailer with a better ability to control the inventory after the start of the selling season, allowing a portion of the demand to be anticipated in advance, thereby reducing some of the risks of a stockout and enabling the retailer to collect more profits. In this work, we describe a hybrid transshipment policy, which attempts to combine the best features of the two types of transshipment. Such a hybrid strategy can quickly cope with shortages by allowing transshipments whenever needed. Meanwhile, the proposed policy also seeks to balance the inventory between the sending and receiving retailers to avoid a sharp shortage that eventually leads to a stockout [8].

However, the structure of a hybrid transshipment policy may be affected by customer switching. Moreover, the complexity of the structure of a hybrid transshipment policy is exacerbated by its interaction with the customer switching behaviour. Thus, retailers should take these two important factors into consideration before making ordering decisions. Under such settings, a customer, who cannot obtain a desired product from a specific retailer, may visit other retailers in search for the desired product. Anticipating that some customers may switch from out-of-stock retailers and that retailers with a surplus typically face an inventory rationing decision, we pose the following question: Is it optimal to accept a request as long as there is available inventory, or is it more profitable to deny the request and reserve some inventory to avoid potential future stockouts? Since the profit generated from selling a product to customers is often higher than that from transshipment to another retailer, the retailer with a surplus has an incentive to reserve some inventory for potential switching demand in the future. And the number of potential customers and the size of their demands are both uncertain. Consequently, the surplus retailer also faces a risk of reserving more inventory than ultimately needed. A further complication results from the fact that the switching demand may be influenced by the hybrid transshipment decision. If a retailer with a surplus inventory reserves less inventory by shipping more of the pertinent product to a retailer suffering a shortage, more demands submitted to the former retailer in the future might be unfulfilled and, thus, more of this retailer's customers may switch to other retailers. Therefore, we will explore how a hybrid transshipment policy and retailers' ordering decisions are impacted by such customer switching behaviour. If a retailer ends up having a surplus inventory after demand realization, the surplus inventory may be sold at a higher price to switching customers. On the other hand, a retailer with inventory shortage may accept less transshipment because a surplus retailer may reserve some inventory for switchingcustomer demands. Therefore, the ordering decisions should also be adapted accordingly. Our aim is to explore how ordering decisions are made under customer switching behaviour and a hybrid transshipment policy.

In particular, we are interested in investigating the following research questions in this work:

(1) Do retailers always gain more profits in the presence of a hybrid transshipment policy and customer switching behaviour?

(2) What is the best transshipment policy for a firm with a surplus inventory or a stockout? How is the transshipment policy affected by the selling periods and the inventories of the other retailers?

(3) Does an optimal ordering Nash equilibrium between two retailers exist?

(4) How does the customer switching behaviour affect the hybrid transshipment policy, the ordering quantity, and the profits?

To address the aforementioned questions, a discrete dynamic programming framework of two independent retailers is developed to seek the optimal hybrid transshipment policy and ordering policy with customer switching behaviour. In addition, simulations and experiments are developed for investigating how the optimal transshipment policy, the ordering quantity, and the profits are affected by the switching rate.

The rest of this paper is organized as follows. Section 2 provides a brief review of the relevant literature, while Section 3 states the problem description and assumptions and presents our analysis framework. In Section 4, we formulate a hybrid two-retailer transshipment model and provide the associated hybrid transshipment policy. We show in Section 5 the existence of an ordering Nash equilibrium for two retailers, taking into consideration the hybrid transshipment policy and customer switching behaviour. Section 6 explores numerically the relationship among the optimal transshipment policy, the ordering quantity, the profits, and customer switching behaviour. Finally, conclusions are given in Section 7. Proofs for all of our mathematical results are provided in the Appendix.

\section{Literature Review}

Extensive research work has been devoted to the study of transshipment policies, which are typically categorized into preventive and reactive transshipments. When the selling season consists of two periods or more, retailers may develop a preventive transshipment to face the risks of a stockout or an overstock. Preventive transshipment policies, first introduced by Gross [9], are used in a two-location system to 
optimize both of the ordering and redistribution decisions at the beginning of the review period. Hoadley and Heyman [10] considered the case when the preventive transshipment is used before the selling season starts, and they provided conditions and an algorithm for implementing the transshipment. Rong et al. [11] proposed a two-period model with a preventive transshipment at the start of the second period and proved the forms of the optimal replenishment and transshipment policy. For a decentralized system, Liao et al. [12] studied the optimal lateral transfer and replenishment decisions, and a multistage stochastic model is established to capture demand uncertainty and customer switching behavior. Dan et al. [13] developed a preventive transshipment policy for two independent retailers that are dominated by the manufacturer. Feng et al. [14] proved the existence and uniqueness of the ordering Nash equilibrium and proposed a more economical transshipment policy. Dehghani et al. [15] considered the hospital can transship blood to other ones in each review period in a network of hospitals and adopted quasi-Monte Carlo sampling approach to conduct stability tests.

An obvious limitation of the papers above is that they focus on the two-period model of preventive transshipment, while retailers practically implement preventive transshipments not only once but more often. Furthermore, Agrawal et al. [16] find that, with increasing transshipment opportunities, retailers may obtain more profits. Therefore, recent research has focused on models with more than two periods. To achieve this, Zhao et al. [7] built a dynamic-programming cost-minimization model and demonstrated a decrease in the optimal transshipment upper level as a function of the inventory level. In addition, Roodbergen [17] rebalanced the logistic costs and derived the optimal decisions for rebalancing and transshipment by stochastic dynamic programming. Based on earlier work, Pang et al. [18] showed that the optimal ordering policy is characterized by a reorder point, while the optimal rationing policy is characterized by time-dependent rationing levels. Feng et al. [19] formulated a Markov decision process to figure out the timing and quantity of preventive transshipment decisions in a multilocation inventory system when both transshipments and emergency orders are available. Van Wijk et al. [20] considered an inventory model in which demands can be fulfilled from a transshipment. They used dynamic programming to show that a threshold-type policy is the best transshipment policy. Aiming at the inventory routing problem with transshipment and substitution under stochastic demand, a mixed-integer linear programming model is proposed. In order to solve this problem, Feaa et al. [21] use the sample average approximation method. The objective is to minimize the cost of holding inventory, transportation (including regular shipment and transshipment), and substitution and sales losses. However, they did not explore the relationships among the transshipment policy, inventory levels, and selling periods in a multiperiod setting.

Most literatures concentrate on reactive or preventive transshipment. In a paper of Paterson et al. [22], we can find there are only four literatures about hybrid transshipment before 2011. As far as we know, only a few studies have begun to consider hybrid transshipment in recent years. In the paper of Teunter et al. [23], a hybrid method is proposed for the first time, which regards transshipment as an opportunity for stock redistribution. The system cost can be reduced, and the efficiency of the transportation process is improved by this hybrid transshipment. Under a continuous review replenishment system, Paterson et al. [24] analysed the first "hybrid" transshipment policy, which seeks to ensure the interests of both by strengthening the traditional reactive approach. Glazebrook et al. [25] pointed out that hybrid transshipment made up for the shortcomings of reactive or preventive transshipment. On the one hand, preventive transshipment takes advantage of economies of scale and reduces the risk of future shortage; on the other hand, reactive transshipment ensures that demand is met immediately upon arrival. Nakandala et al. [26] developed hybrid transshipment that can optimize the cost of backordering and hybrid transshipment policy with considering the trade-off between purchasing, holding, and backorder cost.

Moreover, the structure of a hybrid transshipment policy is typically affected by customer switching behaviour. The interaction between the transshipment policy and customer switching behaviour exacerbates the complexity of the structure of a transshipment policy. Therefore, retailers should take both factors into consideration. Zhao and Atkins [27] explored how transshipments between competing retailers affect their transshipment policies with a fraction of the unsatisfied customers turning to the competitors for a substitute. Liao et al. [28] proposed a centralized model for comparing the strategies of emergency ordering and lateral transshipments under customer switching behaviour. In contrast, Li et al. [29] have considered random switch rates, which led to a more general model that is closer to the real world. Departing from Liao et al. [28], Zhang et al. [30] constructed a model considering the coexistence of transshipment and inventory competition. Some customers may still turn to its competitors even if a retailer that is out of stock provides transshipment service, whereas Liao et al. [28] assumed there exists no inventory competition between the retailers; in other words, there is no customer switching among them. Based on this, Silbermayr [31] developed a framework of multiple retailers. Different from these, Yang et al. [32] proposed cooperative and uncooperative inventory strategies in a dual-channel system with customer switching. They proved the existence and uniqueness of a Nash equilibrium under both strategies, and they also investigated the effects of the transshipment cost and the channel substitution rate on the optimal order quantities under each inventory strategies. However, they focused on a one-time transshipment at each replenishment cycle, thus limiting the exploration of the impact of the customer switching behaviour on transshipment policies. To address these issues, Cömez et al. [33] investigated how a retailer rejects or accepts a transshipment request from a competing retailer when unsatisfied customers switch and showed that optimal transshipment policies are dynamic and chronologically nonincreasing. In addition, Fan et al. [34] constructed inventory models for dual-channel supply chains in 
which inventory competition is induced by customer shifts, while inventory cooperation emerges from transshipment policies. They found the equilibrium-state probability for on-hand inventory. However, one assumption is that one retailer is out of stock, while another retailer is overstocked. This assumption cannot fully reflect the preventive transshipment characteristics of reducing the potential stockout risk. Hence, Cömez et al. [33] and Fan et al. [34] cannot solve the problem that customers who are unsatisfied with stockouts may switch to other retailers.

To summarize, two points distinguish our present work from other approaches:

(1) Our work is the first attempt to examine the relationship between the hybrid transshipment policy and the customer switching behaviour in a decentralized system. The interaction between these two factors is known to exacerbate the complexity of the structure of a transshipment policy. We model this interaction and stress the importance of taking these two factors into consideration before making an ordering decision.

(2) Our work derives and characterizes the optimal hybrid transshipment policy structure with customer switching behaviour. To achieve this, we employ stochastic dynamic programming to model this inventory problem as a dynamic decision problem and describe the optimal policy structure as a thresholdtype policy.

\section{Problem Description and Assumptions}

We consider here two independent retailers who sell a perishable product of the same type during the selling season in two independent dispersed markets. At the beginning of the sales season, the two retailers simultaneously decide their respective order quantities $Q_{i}(i=1,2)$ with no knowledge of future demands. Once the sales season begins, replenishment is prohibited throughout the sales season as the procurement lead time well exceeds the selling season time span. The selling season is finite and is divided into equallength $N$ periods. Through this time division, each cycle is very short, and there can only be at most one unit demand per cycle. If such a unit demand exists, it will be submitted to exactly one of the two retailers. For each period, demands arrive, respectively, at retailers 1 or 2 following homogeneous Poisson's processes with arrival rates of $\lambda_{1}$ and $\lambda_{2}$, where $0 \leq \lambda_{1}+\lambda_{2} \leq 1$. Based on the literature, each arrival represents a single customer who purchases at most one unit of the pertinent product $[20,33]$. According to the agreedupon definition, the first retailer (retailer $i$ or retailer 1 ) is referred to as "he," while the second retailer (retailer $j$ or retailer 2) is referred to as "she."

The first retailer (retailer $i$ ) has three options when he receives a demand. The first option is that the retailer fulfils the demand by his own stock if there is positive on-hand inventory. The second option is a transshipment, which means that a unit is transshipped from retailer $j(j=3-i)$ if she has positive on-hand inventory. The third option is that the retailer rejects the customer. This may lead this unsatisfied customer to turn to retailer $j$ with a switching rate $\theta_{i} \in[0,1]$. Otherwise, the unsatisfied customer will leave the market of these two independent retailers with a probability $1-\theta_{i}$, thereby redirecting the demand to an external market. Until the end of the selling season, the number of remaining periods is denoted by $k, k=N, N-1, \ldots, 1$, and the ordered products arrive before the period $k=N$. The sequence of the events at the selling period $k$ is as follows:

Step 1. At the beginning of the selling season, set $k=N$. The two retailers decide simultaneously their individual order quantities $Q_{i}$ with a unit cost $w$ and without beforehand demand knowledge.

Step 2.1. When a demand arrives at the retailer $i$ at period $k(k>1)$, he may fulfil the demand with his onhand inventory if he has positive on-hand inventory, may send a transshipment request to retailer $j$, or may reject the customer if he experiences a stockout. The retailer's goal in deciding which of the three options to choose is to maximize his profit. Retailer $i$ earns a perunit selling price $p$ if he fulfils the demand by himself. For the second option, retailer $j$ will reply to a transshipment request by making a comparison of the profits she obtains when she accepts or rejects the request. Retailer $j$ can earn the predetermined transshipment price $p_{t}$ if she accepts the request. Retailer $i$ incurs a per-unit transport cost $c_{t}$, a delay cost $n_{i}$, and the cost of the transshipment price $p_{t}$ given to retailer $j$. The unsatisfied customer switches to retailer $j$ with a probability $\theta_{i}$ or leaves the market of these two independent retailers with a probability $1-\theta_{i}$ if retailer $j$ also rejects the request. A per-unit shortage cost $m_{i}$ is incurred by retailer $i$ if he rejects the customer.

Step 2.2. When a demand arrives at retailer $j$ at period $k$, and if she sends a transshipment request to retailer $i$, retailer $i$ accepts or rejects the request by making a comparison of the profits he obtains. Retailer $i$ earns a per-unit transshipment price $p_{t}$ if he accepts the request. Otherwise, he earns a per-unit selling price $p_{i}$ if he fulfils the unsatisfied demand from retailer $j$.

Step 2.3. When no demand arrives at either of the retailers in period $k$, retailer $i$ makes a decision whether to keep the inventory unchanged and send a request of transshipment to retailer $j$ to transship a unit in or transship a unit out.

Step 3. At the end of the selling season, if there is an excess inventory, then this inventory is salvaged with a unit salvage value of $s_{i}$.

As well, other assumptions are made in this work. We assume $p_{t}+c_{t}+n_{i} \leq p_{i}+m_{i}$ and $p_{t} \geq w \geq s_{i}$. The former assumption ensures that transshipping in a unit is beneficial. The latter assumption ensures that transshipping out a unit is beneficial and that there is no opportunity for the arbitrage by salvaging the product. 


\section{Hybrid Transshipment Policy}

4.1. Model Formulation. In this section, we build a dynamic programming model that we utilize to optimize the hybrid transshipment and ordering policy, thereby solving the problem described in Section 3. We denote the state of the system by $x=\left(x_{1}, x_{2}\right)$, where $x_{1}, x_{2}$ are nonnegative integers that indicate the inventory levels for the two retailers, respectively, where $0 \leq x_{1} \leq Q_{1}, 0 \leq x_{2} \leq Q_{2}$. The state space $S$ described by $x$ covers all possible inventory level combinations: $S=\left\{0,1, \ldots, Q_{1}\right\} \times\left\{0,1, \ldots, Q_{2}\right\}$. Uniformization [35] is applied to convert the decision problem from the semi-Markov type into the equivalent Markov-type one. For making a decision, the direct and future expected revenues should be taken into account. For a given state, we measure the expected profits using the value function, $v_{k}^{i}\left(x_{1}, x_{2}\right)$, which is the maximum expected total profit when there are $k$ remaining periods starting in state $\left(x_{1}, x_{2}\right) \in S$. For the whole selling season, three events may occur. At most, one demand unit arrives at either retailer 1 or retailer 2. For the convenience of reading, we have listed the parameters in Table 1.

Without loss of generality, we take retailer 1 as an example to develop the state-transition model. The inventory levels and the remaining selling periods are described by a three-dimensional vector. Therefore, the formulation of this process can be expressed as follows:

$$
v_{k}^{1}\left(x_{1}, x_{2}\right)=\lambda_{1} H_{1} v_{k-1}^{1}\left(x_{1}, x_{2}\right)+\lambda_{2} H_{2} v_{k-1}^{1}\left(x_{1}, x_{2}\right)+\left(1-\lambda_{1}-\lambda_{2}\right) H_{3} v_{k-1}^{1}\left(x_{1}, x_{2}\right),
$$

where $H_{1} v_{k-1}^{1}\left(x_{1}, x_{2}\right), H_{2} v_{k-1}^{1}\left(x_{1}, x_{2}\right)$, and $H_{3} v_{k-1}^{1}\left(x_{1}, x_{2}\right)$ are the operators of the expected profits of the three events.
These operators are defined by equations (2)-(5), respectively. The first operator is defined as

$$
\begin{aligned}
& H_{1} v_{k-1}^{1}\left(x_{1}, x_{2}\right) \\
& = \begin{cases}p_{1}+\max \left\{-w+v_{k-1}^{1}\left(x_{1}-1, x_{2}\right),\left[-p_{t}-c_{t}+v_{k-1}^{1}\left(x_{1}, x_{2}-1\right)+M\right] \mathrm{I}_{1, k-1}^{2}-M\right\}, & x_{1} \geq 1, x_{2} \geq 1, \\
p_{1}-w+v_{k-1}^{1}\left(x_{1}-1, x_{2}\right), & x_{1} \geq 1, x_{2}=0, \\
\max \left\{\left[p_{1}-p_{t}-c_{t}-n_{1}+v_{k-1}^{1}\left(x_{1}, x_{2}-1\right)+M\right] \mathrm{I}_{2, k-1}^{2}-M, \theta_{1} v_{k-1}^{1}\left(x_{1}, x_{2}-1\right)+\left(1-\theta_{1}\right) v_{k-1}^{1}\left(x_{1}, x_{2}\right)-m_{1}\right\}, & x_{1}=0, x_{2} \geq 1, \\
v_{k-1}^{1}\left(x_{1}, x_{2}\right)-m_{1}, & x_{1}=0, x_{2}=0,\end{cases}
\end{aligned}
$$

where $M$ is a very large real number, which satisfies the condition $M \gg \max \left\{v_{k}^{1}\left(x_{1}, x_{2}\right), v_{k}^{2}\left(x_{1}, x_{2}\right)\right\}$ for all $k$ and $\left(x_{1}, x_{2}\right) \in S$. In the first condition $x_{1} \geq 1, x_{2} \geq 1$, a preventive transshipment from retailer 2 to retailer 1 can occur. In the third condition $x_{1}=0, x_{2} \geq 1$, a reactive transshipment from retailer 2 to retailer 1 can occur. The indicator variables $I_{1, k-1}^{2}$ and $I_{2, k-1}^{2}$ are defined by

$$
\begin{aligned}
I_{1, k-1}^{2} & = \begin{cases}1, & v_{k-1}^{2}\left(x_{1}, x_{2}-1\right)-v_{k-1}^{2}\left(x_{1}-1, x_{2}\right) \geq-p_{t}+w, \\
0, & \text { otherwise }\end{cases} \\
I_{2, k-1}^{2} & = \begin{cases}1, & p_{t}-w+v_{k-1}^{2}\left(x_{1}, x_{2}-1\right) \geq \theta_{1}\left(p_{2}-w+v_{k-1}^{2}\left(x_{1}, x_{2}-1\right)\right)+\left(1-\theta_{1}\right) v_{k-1}^{2}\left(x_{1}, x_{2}\right), \\
0, & \text { otherwise. }\end{cases}
\end{aligned}
$$

The formula in (2) represents the expected profit of retailer 1 when he receives a demand with an arrival rate $\lambda_{1}$ in the selling period $k$. Retailer 1 has an optimized inventory at the beginning of this period, and it is impossible to transship one unit out if he has satisfied the demand of one unit. Therefore, the decision of transshipping in one product unit from retailer 2 has been made after fulfilling one unit of demand in the state $x_{1} \geq 1, x_{2} \geq 1$. And retailer 2 must accept the transshipment request of retailer 1 , when the inequality $\quad v_{k-1}^{2}\left(x_{1}, x_{2}-1\right)-v_{k-1}^{2}\left(x_{1}-1, x_{2}\right) \geq-p_{t}+w$ holds. Otherwise, the inventory of retailer 1 remains unchanged. For the state $x_{2}=0$, he cannot adjust the inventory because retailer 1 cannot transship in one unit. When the inventory status of the two retailers is $x_{1}=0, x_{2} \geq 1$, retailer 1 can fulfil the demand by transshipping in one unit if retailer 2 accepts the transshipment request; that is, the inequality $\quad p_{t}-w+v_{k-1}^{2}\left(x_{1}, x_{2}-1\right) \geq \theta_{1}\left(p_{2}-w+v_{k-1}^{2}\right.$ $\left.\left(x_{1}, x_{2}-1\right)\right)+\left(1-\theta_{1}\right) v_{k-1}^{2}\left(x_{1}, x_{2}\right)$ holds. Retailer 1 incurs a delay cost $n_{1}$. Otherwise, a per-unit shortage cost $m_{1}$ is incurred by retailer 1 . The second operator is defined as 
TABLE 1: List of notations.

\begin{tabular}{lc}
\hline$\lambda_{i}$ & Arrival rates of retailer $i$ \\
$Q_{i}$ & Order quantities of retailer $i$ \\
$\theta_{i}$ & Switching rate of retailer $i$ \\
$p_{i}$ & Selling price of retailer $i$ \\
$k$ & Number of remaining periods \\
$w$ & A unit cost of ordering \\
$c_{t}$ & Transport cost of retailer $i$ \\
$n_{i}$ & Delay cost of retailer $i$ \\
$m_{i}$ & Shortage cost \\
$p_{t}$ & Predetermined transshipment price of retailer $i$ \\
$s_{i}$ & Salvage value of retailer $i$ \\
$x_{i}$ & Inventory levels of retailer $i$ \\
$S$ & The state space \\
$v_{k}^{i}\left(x_{1}, x_{2}\right)$ & Transhipment lower levels for retailer $i$ \\
$P O T_{k}^{i}\left(x_{j}\right)$ & Transshipment upper levels for retailer $i$ \\
$P I T_{k}^{i}\left(x_{j}\right)$ & Maximum expected total profit when there are $k$ remaining periods state $\left(x_{1}, x_{2}\right) \in S$ \\
\hline
\end{tabular}

$$
\begin{aligned}
& H_{2} v_{k-1}^{1}\left(x_{1}, x_{2}\right) \\
& = \begin{cases}\max \left\{v_{k-1}^{1}\left(x_{1}, x_{2}-1\right),\left[p_{t}-w+v_{k-1}^{1}\left(x_{1}-1, x_{2}\right)+M\right] \mathrm{I}_{3, k-1}^{2}-M\right\}, & x_{1} \geq 1, x_{2} \geq 1 \\
\max \left\{p_{t}-w+v_{k-1}^{1}\left(x_{1}-1, x_{2}\right), \theta_{2}\left(p_{1}-w+v_{k-1}^{1}\left(x_{1}-1, x_{2}\right)\right)+\left(1-\theta_{2}\right) v_{k-1}^{1}\left(x_{1}, x_{2}\right)\right\}, & x_{1} \geq 1, x_{2}=0 \\
v_{k-1}^{1}\left(x_{1}, x_{2}-1\right), & x_{1}=0, x_{2} \geq 1 \\
v_{k-1}^{1}\left(x_{1}, x_{2}\right), & x_{1}=0, x_{2}=0\end{cases}
\end{aligned}
$$

The indicator variable $I_{3, k-1}^{2}$ is defined by $I_{3, k-1}^{2}=$ $\begin{cases}1, & v_{k-1}^{2}\left(x_{1}-1, x_{2}\right)-v_{k-1}^{2}\left(x_{1}, x_{2}-1\right) \geq p_{t}+c_{t}-w \\ 0, & \text { otherwise }\end{cases}$

The formula in (4) represents the expected profit of retailer 2 when she receives a demand with arrival rate $\lambda_{2}$ in the selling period $k$. Retailer 2 has an optimized inventory at the beginning of this period, and it is also impossible to transship out (a preventive transshipment) the product if she has satisfied the demand of one unit. Therefore, the decision to transship out one product unit to retailer 1 has been made after receiving a transshipment request from retailer 1 in the state $x_{1} \geq 1, x_{2} \geq 1$. For the state $x_{1}=0$, retailer 2 cannot adjust the inventory because retailer 1 cannot transship out one unit of product. For the two retailers, when the inventory status is $x_{1} \geq 1, x_{2}=0$, retailer 2 must send a transshipment request (a reactive transshipment) to retailer 1 because there has no inventory for her to satisfy the demand. Further, retailer 1 will make a decision whether to accept or reject the transshipment request by making a comparison of the profits he obtains because there is enough surplus inventory to meet the switching demand from retailer 2. The third operator is defined as

$$
\begin{aligned}
& H_{3} v_{k-1}^{1}\left(x_{1}, x_{2}\right) \\
& =\left\{\begin{array}{lr}
\max \left\{v_{k-1}^{1}\left(x_{1}, x_{2}\right),\left[-p_{t}-c_{t}+w+v_{k-1}^{1}\left(x_{1}+1, x_{2}-1\right)+M\right] I_{4, k-1}^{2}-M,\left[p_{t}-w+v_{k-1}^{1}\left(x_{1}-1, x_{2}+1\right)+M\right] \mathrm{I}_{5, k-1}^{2}-M\right\}, & x_{1} \geq 1, x_{2} \geq 1, \\
\max \left\{v_{k-1}^{1}\left(x_{1}, x_{2}\right),\left[-p_{t}-c_{t}+w+v_{k-1}^{1}\left(x_{1}+1, x_{2}-1\right)+M\right] \mathrm{I}_{6, k-1}^{2}-M\right\}, & x_{1}=0, x_{2} \geq 1, \\
\max \left\{v_{k-1}^{1}\left(x_{1}, x_{2}\right), p_{t}-w+v_{k-1}^{1}\left(x_{1}-1, x_{2}+1\right)\right\}, & x_{1} \geq 1, x_{2}=0, \\
v_{k-1}^{1}\left(x_{1}, x_{2}\right) & x_{1}=0, x_{2}=0 .
\end{array}\right.
\end{aligned}
$$

The indicator variables $I_{4, k-1}^{2}, I_{5, k-1}^{2}$, and $I_{6, k-1}^{2}$ are defined as follows: 


$$
\begin{aligned}
& I_{4, k-1}^{2}= \begin{cases}1, & v_{k-1}^{2}\left(x_{1}+1, x_{2}-1\right)-v_{k-1}^{2}\left(x_{1}, x_{2}\right) \geq-p_{t}+w, \\
0, & \text { otherwise }\end{cases} \\
& \mathrm{I}_{5, k-1}^{2}= \begin{cases}1, & v_{k-1}^{2}\left(x_{1}-1, x_{2}+1\right)-v_{k-1}^{2}\left(x_{1}, x_{2}\right) \geq p_{t}-w+c_{t}, \\
0, & \text { otherwise }\end{cases} \\
& \mathrm{I}_{6, k-1}^{2}= \begin{cases}1, & v_{k-1}^{2}\left(x_{1}+1, x_{2}-1\right)-v_{k-1}^{2}\left(x_{1}, x_{2}\right) \geq-p_{t}+w, \\
0, & \text { otherwise. }\end{cases}
\end{aligned}
$$

The formula in (5) represents the expected profits of retailer 1 when no demand arrives at the selling period $k$. Retailer 1 can choose to keep the inventory unchanged and send a transshipment request to transship in or out one unit. Except the fourth condition $x_{1}=0, x_{2}=0$, a preventive transshipment from retailer 2 to retailer 1 or from retailer 1 to retailer 2 can occur. However, retailer 2, while determining how to obtain her maximum profit, must either accept or reject the transshipment request.

For $k=1$, besides the sale, the excess inventory is salvaged. In this case, the expected profit of retailer 1 is given by

$$
\begin{aligned}
& v_{1}^{1}\left(x_{1}, x_{2}\right) \\
& = \begin{cases}\lambda_{1}\left[p_{1}-w+\left(s_{1}-w\right)\left(x_{1}-1\right)\right]+\left(1-\lambda_{1}\right)\left(s_{1}-w\right) x_{1}, & x_{1} \geq 1, x_{2} \geq 1, \\
\lambda_{1}\left[p_{1}-w+\left(s_{1}-w\right)\left(x_{1}-1\right)\right]+\left(1-\lambda_{1}-\lambda_{2}\right)\left(s_{1}-w\right) x_{1} & x_{1} \geq 1, x_{2}=0, \\
+\lambda_{2} \max \left\{p_{t}-w+\left(s_{1}-w\right)\left(x_{1}-1\right), \theta_{2}\left(p_{1}-w+\left(s_{1}-w\right)\left(x_{1}-1\right)\right)+\left(1-\theta_{2}\right)\left(s_{1}-w\right) x_{1}\right\}, & x_{1}=0, x_{2} \geq 1, \\
\lambda_{1} \max \left\{\left(p_{1}-p_{t}-c_{t}-n_{1}+M\right) I_{7,1}^{2}-M,-m_{1}\right\}, & x_{1}=0, x_{2}=0 . \\
-\lambda_{1} m_{1}, & \end{cases}
\end{aligned}
$$

The indicator variable $I_{7,1}^{2}$ is defined by

$$
I_{7,1}^{2}= \begin{cases}1, & p_{t} \geq \theta_{1} p_{2}+\left(1-\theta_{1}\right) s_{2}, \\ 0, & \text { otherwise. }\end{cases}
$$

4.2. Benefits from the Hybrid Transshipment Policy. A retailer always prefers selling the products to transferring the order to another retailer when a hybrid transshipment is not allowed. Therefore, such a retailer will have no impact on the other retailer when a customer arrives. However, when a customer arrives at the other retailer, the first retailer can meet the switching demand if he has enough surplus inventory while another retailer stocks out. Without loss of generality, we take retailer 1 as an example to develop the formulation for this process when there is no transshipment as follows:

$$
v_{k}^{N 1}\left(x_{1}, x_{2}\right)=\lambda_{1} H_{1} v_{k-1}^{N 1}\left(x_{1}, x_{2}\right)+\lambda_{2} H_{2} v_{k-1}^{N 1}\left(x_{1}, x_{2}\right)+\left(1-\lambda_{1}-\lambda_{2}\right) v_{k-1}^{N 1}\left(x_{1}, x_{2}\right)
$$

where $H_{1} v_{k-1}^{N 1}\left(x_{1}, x_{2}\right)$ and $H_{2} v_{k-1}^{N 1}\left(x_{1}, x_{2}\right)$ are the expected profit operators defined by the following formulas:

$$
\begin{aligned}
& H_{1} v_{k-1}^{N 1}\left(x_{1}, x_{2}\right)= \begin{cases}p_{1}-w+v_{k-1}^{N 1}\left(x_{1}-1, x_{2}\right), & x_{1} \geq 1, \\
\theta_{2} v_{k-1}^{N 1}\left(x_{1}, x_{2}-1\right)+\left(1-\theta_{2}\right) v_{k-1}^{N 1}\left(x_{1}, x_{2}\right)-m_{1}, & x_{1}=0, x_{2} \geq 1, \\
v_{k-1}^{N 1}\left(x_{1}, x_{2}\right)-m_{1}, & x_{1}=0, x_{2}=0,\end{cases} \\
& H_{2} v_{k-1}^{N 1}\left(x_{1}, x_{2}\right)= \begin{cases}v_{k-1}^{N 1}\left(x_{1}, x_{2}-1\right), & x_{2} \geq 1, \\
\theta_{2}\left(p_{1}-w+v_{k-1}^{N 1}\left(x_{1}-1, x_{2}\right)\right)+\left(1-\theta_{2}\right) v_{k-1}^{N 1}\left(x_{1}, x_{2}\right), & x_{1} \geq 1, x_{2}=0, \\
v_{k-1}^{N 1}\left(x_{1}, x_{2}\right), & x_{1}=0, x_{2}=0 .\end{cases}
\end{aligned}
$$


The formula in (10) represents the expected profit of retailer 1 at period $k$ when a customer is received. The formula in (11) shows the profit of retailer 1 when a customer is received at retailer 2 . At period $k=1$, since the inventory cannot be adjusted at this period, the expected profit is defined by

$$
v_{1}^{N 1}\left(x_{1}, x_{2}\right)= \begin{cases}\lambda_{1}\left[p_{1}-w+\left(s_{1}-w\right)\left(x_{1}-1\right)\right]+\left(1-\lambda_{1}\right)\left(s_{1}-w\right) x_{1}, & x_{1} \geq 1, x_{2} \geq 1, \\ \lambda_{1}\left(p_{1}-w\right)+\left(s_{1}-w\right)\left(-\lambda_{1}+x_{1}-\theta_{2} \lambda_{2}\right)+\lambda_{2} \theta_{2}\left(p_{1}-w\right), & x_{1} \geq 1, x_{2}=0 \\ -\lambda_{1} m_{1}, & x_{1}=0 .\end{cases}
$$

The question whether a hybrid transshipment policy is more profitable for the two retailers is addressed by Theorem 1 .

Theorem 1. If $p_{t} \in\left[w, p_{i}+m_{i}-c_{t}-n_{i}\right]$, more profits can be collected with a hybrid transshipment policy compared to the case of no such policy.

Theorem 1 indicates that more benefits can be extracted from a hybrid transshipment policy than the nontransshipment strategy; when the transshipment price is within a certain range, this motivates the two retailers to transship in or out one unit. On the one hand, the two retailers can react to the shortage by implementing a reactive transshipment. Moreover, this customer switching behaviour makes the retailer obtain more profit than without switch. On the other hand, the two retailers can balance the inventory even if there is no demand, hence providing an additional tool to match the supply and demand. Therefore, the two retailers can benefit from the implementation of a hybrid transshipment policy. Meanwhile, Theorem 1 also indicates that whether two retailers can obtain more profits has no relation with customer switching rate although the switch makes the retailer collect more profits.
4.3. Reactive Transshipment Policy. Recall that when there is no inventory, it is optimal to directly use a reactive transshipment to meet demand. Therefore, a retailer will send a transshipment request to the other retailer if a retailer is stocked-out upon a customer demand during the selling season. However, the other retailer cannot always accept the transshipment request due to the anticipated demand of the remaining periods, even if she has available on-hand inventory because she would only obtain transshipment revenue, which is lower than the regular selling price. Hence, she must make a trade-off between the transshipment revenue and the expected revenue from the anticipated sale. The critical inventory level above which she decides to share her inventory is called the holdback level. This parameter limits the quantity of the outgoing reactive transshipments and indicates that the level of the inventory is held back from a reactive transshipment request. Thus, we call this policy a holdback policy [20].

Theorem 2. For $x_{j}=0$, there is a holdback policy, which is best for retailer $i$. The holdback level is defined by

$$
\operatorname{ROT}_{k}^{i}=\min \left\{x_{i}: v_{k}^{i}\left(x_{i}, 0\right)-v_{k}^{i}\left(x_{i}-1,0\right) \leq \frac{p_{t}-w-\theta_{j}\left(p_{i}-w\right)}{1-\theta_{j}}\right\},
$$

where $\mathrm{ROT}_{k}^{i}$ is nondecreasing in the number of remaining periods for all $R_{0} T_{k}^{i} \in\left\{3,4, \ldots, Q_{i}\right\}$. If $\theta_{j}>\left(p_{t}-s_{i}\right)$ $/\left(p_{i}-s_{i}\right)$, retailer $i$ will always reject the request of retailer $j$.

Theorem 2 specifies the existence of the holdback policy and the monotonicity of the holdback level in each decision period. The retailer should transship out the product when there is more inventory or fewer periods remaining. For better understanding of this trade-off, we define $\Delta_{k}^{i}\left(x_{i}\right)=v_{k}^{i}\left(x_{i}, 0\right)-v_{k}^{i}\left(x_{i}-1,0\right)$, which denotes the marginal benefit of holding a unit of inventory for retailer $i$ when $x_{j}=0$. Intuitively, when the inventory level is higher for retailer $i$, the marginal benefit of an inventory unit is the same or lower. Therefore, $\Delta_{k}^{i}\left(x_{i}\right)$ is nonincreasing in $x_{i}$, which demonstrates that there is a holdback level to accept/reject retailer $j$. The holdback level monotonicity implies that the retailer has higher marginal revenue to reject requests early in the sales season. Therefore, the retailer should transship out the product when there are fewer periods left in the whole sale season. A transshipment strategy is based on the trade-off between selling an inventory unit and keeping it for a potential product sale. Therefore, the retailer will reject the request of transshipping in one unit when the switching rate is higher for the other retailer to wait for a potential higher direct customer sale. When the switching rate is large enough, the retailer will always reject the request.

4.4. Preventive Transshipment Policy. A preventive transshipment can be implemented by a retailer to adjust the inventory in some periods when there is no demand for the two retailers. There is no preventive transshipment decision to adjust the inventory at the decision period $k=1$. Similarly, the retailer cannot transship in the product with the inventory $x_{i}=Q_{i}$, while it is impossible to transship out one unit with the inventory $x_{i}=0$. Therefore, an inventory control policy specifies the transshipment upper and lower levels at any period (except $k=1$ ) and any inventory level 
(except $x_{i}=Q_{i}$ and $x_{i}=0$ ). The following theorem formalizes this concept.

Theorem 3. For $k \geq 2$, for the inventory of retailer $j$, $x_{j} \in\left\{1,2, \ldots, Q_{j}\right\}$, some transshipment upper levels
$\operatorname{PIT}_{k}^{i}\left(x_{j}\right) \in\left\{0,1,2, \ldots, Q_{i}-1\right\}$ exist for retailer $i$. Similarly, for the inventory of retailer $j, x_{j} \in\left\{0,1,2, \ldots, Q_{j}-1\right\}$, some transshipment lower levels $P O T_{k}^{i}\left(x_{j}\right) \in\left\{1,2, \ldots, Q_{i}\right\}$ exist for retailer i. $\operatorname{PIT}_{k}^{i}\left(x_{j}\right)$ and $\operatorname{POT}_{k}^{i}\left(x_{j}\right)$ are given by

$$
\begin{aligned}
& \operatorname{PIT}_{k}^{i}\left(x_{j}\right)=\max \left\{x_{i}: v_{k}^{i}\left(x_{i}+1, x_{j}-1\right)-v_{k}^{i}\left(x_{i}, x_{j}\right) \geq p_{t}+c_{t}-w\right\}, \\
& \operatorname{POT}_{k}^{i}\left(x_{j}\right)=\min \left\{x_{i}: v_{k}^{i}\left(x_{i}-1, x_{j}+1\right)-v_{k}^{i}\left(x_{i}, x_{j}\right) \geq-p_{t}+w\right\} .
\end{aligned}
$$

Theorem 3 indicates that there is an inventory control band composed of the thresholds of the transshipment upper and lower levels to decide whether transshipments should be made between the retailers. For each period and each inventory level, critical inventory thresholds exist. These thresholds divide the set into up to three subsets. Once customer demand is received, it is best to send a transshipment-in request to the other retailer only if the inventory level is equal to or lower than the upper level of transshipment. Meanwhile, it is optimal to send a transshipment-out request to the other retailer only when the inventory level is at or above the transshipment upper level. Otherwise, it is optimal to do nothing when the inventory lies between the transshipment upper and lower levels. We have the following proposition.

Proposition 1. For $k \geq 2$, the optimal hybrid transshipment policy is a threshold-type dominant-equilibrium policy. Retailer $i$ should transship in one unit from retailer $j$ if the inventory level satisfies $0 \leq x_{i} \leq P I T_{k}^{i}\left(x_{j}\right)$. Retailer $i$ should transship out one unit from retailer $j$ if the inventory level satisfies $\operatorname{POT}_{k}^{i}\left(x_{j}\right) \leq x_{i} \leq Q_{i}$. Otherwise, retailer $i$ does nothing.

Proposition 1 demonstrates that the preventive transshipment between two retailers can be controlled through a simple decision rule comparing the on-hand and the critical inventory levels. The preventive transshipment policy of a certain retailer is neither related to the demand of the other retailer before this period, nor is it related to the preventive transshipment policy adopted by the other retailer. Therefore, the retailer can control the inventory by the inventory control band composed of the thresholds of the transshipment upper and lower levels without considering the impact of the preventive transshipment policy of the other retailer when observing the inventory of the other retailer at each period. The two thresholds of the preventive transshipment strategy play a key role in the transshipment process. Obtaining the structural threshold properties is necessary for characterizing the optimal transshipment policy. These properties are stated in the following proposition.

Proposition 2. When $k \geq 2, \quad P I T_{k}^{i}\left(x_{j}+1\right) \leq P I T_{k}^{i}\left(x_{j}\right)$, $\operatorname{POT}_{k}^{i}\left(x_{j}+1\right) \leq \operatorname{POT}_{k}^{i}\left(x_{j}\right)$.

Proposition 2 shows that the retailer is not willing to transship in one unit due to the smaller transshipment upper level when there are more inventory units for the other retailer at each period. It is easy to transship in one unit when there are more inventory units for the other retailer. Therefore, the risk of excessive inventory at the end of a period can be avoided by postponing the transshipment. The retailer must transship in one unit in advance to avoid the risk of stockout because the other retailer will most likely reject the request when there is less inventory.

The retailer is prone to transship out the inventory due to the smaller transshipment lower level when there is more inventory for the other retailer at each period because the retailer prefers to transship out one unit to avoid the risk of the excessive inventory at the end of the period. This transfers the risk to the other retailer when there is more inventory for the other retailer.

Proposition 2 also demonstrates that a preventive transshipment is not only a strategic choice to reduce the risk of a stockout, but it is also a strategic option to avoid the leftover inventory risk. The retailer can control the inventory by implementing a preventive transshipment. It is optimal to transship in one unit to avoid the risk of a stockout when there is less inventory for the other retailer and transship out one unit to avoid an overstock risk when there is more inventory for the other retailer.

A preventive transshipment policy ensures that each retailer can control his/her inventory with the prespecified transshipment upper and lower levels after observing the other retailer's inventory. At each selling period, the retailer will transship in one unit as long as the on-hand inventory is less than the transshipment upper level and transship out one when the on-hand inventory is more than the transshipment lower level without considering how the other retailer implements a preventive transshipment policy. In addition, preventive transshipment plays a role in reducing the risk of a stockout or an overstock by transshipping in or transshipping out the product in advance or after a period of time. After obtaining the retailer's preventive transshipment policy, the relationship between transshipments and ordering needs should be analysed further. Therefore, in the next section, we will analyse the retailer's ordering policy.

\section{Ordering Policy}

The implementation of a hybrid transshipment policy allows inventory sharing between the two retailers. This reveals a strategic substitute relation between the two retailers regarding the ordering quantities. That is, the optimal ordering 
quantity of one retailer is not only related to the ordering quantity of the other retailer, but also related to the optimal hybrid transshipment policy of the two retailers at the beginning of the selling season. Therefore, we need to investigate further the existence of ordering Nash equilibrium with a hybrid transshipment policy.

Theorem 4. There is at least one Nash equilibrium for ordering quantities for two retailers.

Theorem 4 shows that, due to the transshipment, there is a strategic substitute relationship of the ordering quantity between two retailers. In fact, the transshipment enables inventory sharing, mitigates the effects of the demand uncertainty, and helps to amend fluctuations of target inventory caused future demand uncertainty. In addition, the transshipment can not only fill stockouts but can also help retailers to balance their inventories. However, Theorem 4 does not guarantee the uniqueness of the Nash equilibrium for the ordering quantities of the two retailers. This is because a different hybrid transshipment policy results in different transshipment lower and upper levels, which further cause a different optimal order quantity.

\section{Numerical Analysis}

The numerical experiments explore the existence of a transshipment area with a switching rate and further analyse the impact of the transshipment cost, switching rate, and arrival rate on the ordering quantity, transshipment policy, and profit. Throughout these experiments, the nominal values for the input parameters are $p_{1}=p_{2}=40$, $m_{1}=m_{2}=10, \quad n_{1}=n_{2}=0, \quad s_{1}=s_{2}=4, \quad c_{t}=0, \quad w=20$, $N=70$, and $\lambda_{1}=0.2$. Following Gruen and Corsten [1], we assume the switching rate to be $\theta_{1}=0.3$.

6.1. Transshipment Area with a Switching Rate. The switching rate is a key model parameter that is likely to impact the hybrid transshipment policy. To assess this impact, a sensitivity analysis is conducted in which three different values covering a wide range are chosen for the switching rate, while keeping all other parameters at their nominal values. At the 30th selling period, the transshipment area between the two retailers is shown in Figure 1 when $\theta_{2}$ is equal to 0.1, 0.3 , and 0.5 .

As shown in Figure 1, the whole area is divided into three ones. Reactive or preventive transshipment occur in area I or area II, but not in area III. Shadow boundary in area I and area II represents the thresholds of the transshipment upper and lower levels. Reactive transshipment occurs when retailer 2 stocks out (i.e., $x_{2}=0$ ) and the inventory of retailer 1 is in area I. Preventive transshipment occurs when retailer 2 has on-hand inventory in area I. There is a similar situation in area II.

When the switching rate of retailer 2 increases, the areas of I and II decrease. The reason is that retailer 1 should be more open to reject a transshipment request to encourage the unsatisfied customer to switch to his location as the switching rate of retailer 2 increases. Therefore, retailer 1 will set a larger transshipment lower level and a smaller transshipment upper level to prevent the transshipment.

\subsection{Sensitivity Analysis}

6.2.1. Ordering Quantity with a Switching Rate. Table 2 depicts the relationship among the ordering quantity, the transshipment price, the arrival rate, and the switching rate of retailer 2 .

As shown in Table 2, the ordering quantity of the two retailers is nondecreasing with the switching rate $\theta_{2}$. The ordering quantity of retailer 1 is sensitive to the change in the switching rate. On the one hand, there is a higher rate of unsatisfied customers switching to retailer 2 when the switching rate $\theta_{2}$ increases, which makes retailer 1 order more to respond to the higher numbers of unsatisfied customers. On the other hand, retailer 1 will reject more transshipment-in requests to make more unsatisfied customers switch to him. Therefore, these two factors together cause a significant increase in the order quantity of retailer 1. However, the order quantity of retailer 2 is less sensitive to the change of the switching rate. Retailer 1 is more willing to reject the transshipment-in requests. This causes retailer 2 to order more. However, this effect is not clearly obvious.

When the transshipment price changes, the two retailers do not significantly adjust the ordering quantity. This is significantly different from the reactive transshipment [36]. When the transshipment price is low, the retailers tend to satisfy the demands of each other, so the ordering quantity is low. However, a retailer has to order more to avoid the risk of a stockout when the transshipment price is high. Consequently, the two retailers are willing to order more. However, the demand information of the next stage is not released due to the preventive transshipment. This makes the retailer bear not only the risk of a stockout but also that of an overstock in the future. Therefore, the retailer has to order more to avoid the risk of a stockout when the transshipment price is low, while lowering the ordering quantity to avoid the excessive inventory at the end of the sale season when the transshipment price is high. So, the two retailers do not significantly adjust the ordering quantity even if the transshipment price has a drastic change due to the preventive transshipment.

6.2.2. Relationship between Transshipment Lower Level, Transshipment Upper Level, and Switching Rate. At the 40th selling period, changes of the transshipment lower and upper levels with the switching rate are shown in Figure 2 when $\theta_{2}$ is equal to $0.1,0.3$, and 0.5 . The transshipment lower and upper levels are nondecreasing in the transshipment price, and the gap between transshipment lower and upper levels becomes increasingly wider as the transshipment price increases. The two retailers set a larger target inventory to avoid the risk of a stockout in the future. This causes them to be unwilling to transship out but willing to transship in when the transshipment price increases. Therefore, the two retailers set higher transshipment lower and upper levels. In 


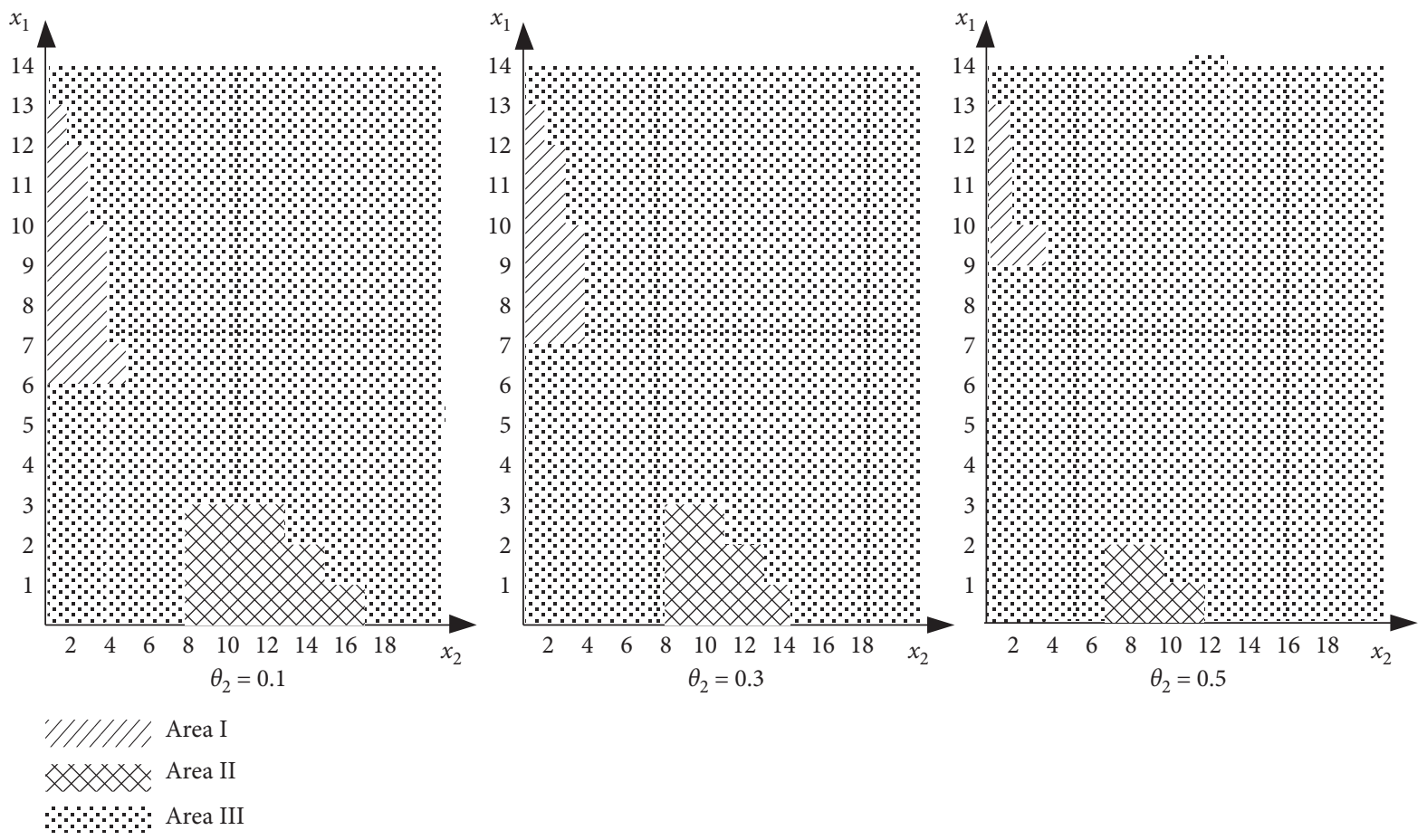

FIgURE 1: Transshipment area with different switching rates.

TABLE 2: The relationship between the ordering quantities of the two retailers with the switching rate.

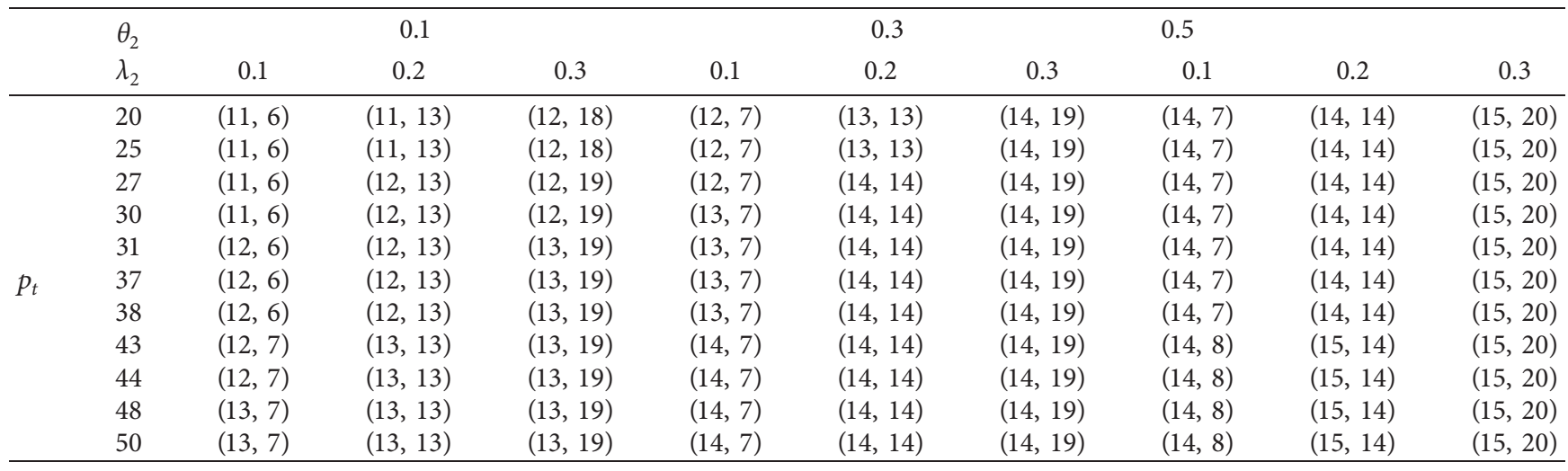

addition, as shown in Figure 2, it is easier to balance the inventory due to the wider gap as the transshipment price increases. The retailer is willing to adjust the inventory by ordering when there is a lower transshipment price and adjust the inventory by transshipment when there is a higher one. The reason is that the ordering policies of the two retailers not only have a strategic substitute relationship, but the ordering and preventive transshipment also have a strategic substitute relationship. Therefore, the retailer tends to control the inventory by setting a higher ordering quantity if the transshipment price is low, while adjusting the inventory with the transshipment policy when the transshipment price is high.

The relationship between the profit of two retailers and switching rate is shown in Figure 3 when $\theta_{2}$ is equal to 0.1 , 0.3 , and 0.5 .
As seen in Figure 3, both retailers can gain a higher profit with transshipment than without transshipment, which is consistent with Theorem 1 . The transshipment provides an additional tool to collect more profit. In addition, the profit of retailer 1 is nondecreasing in the switching rate of retailer 2. As the switching rate of retailer 2 increases, on the one hand, there are increasing numbers of unsatisfied customers switching to retailer 1 due to the higher switching rate. On the other hand, retailer 1 would like to reject the transshipment-in request of retailer 2 to induce the customer switching behaviour. Hence, retailer 1 can gain more profit by satisfying more unsatisfied customers from retailer 2 . However, the profit of retailer 2 is also nondecreasing in her switching rate. There is a different mechanism from that of retailer 1 . Retailer 1 gains more profit by supplying unsatisfied customers, while retailer 2 gains more by bearing more 

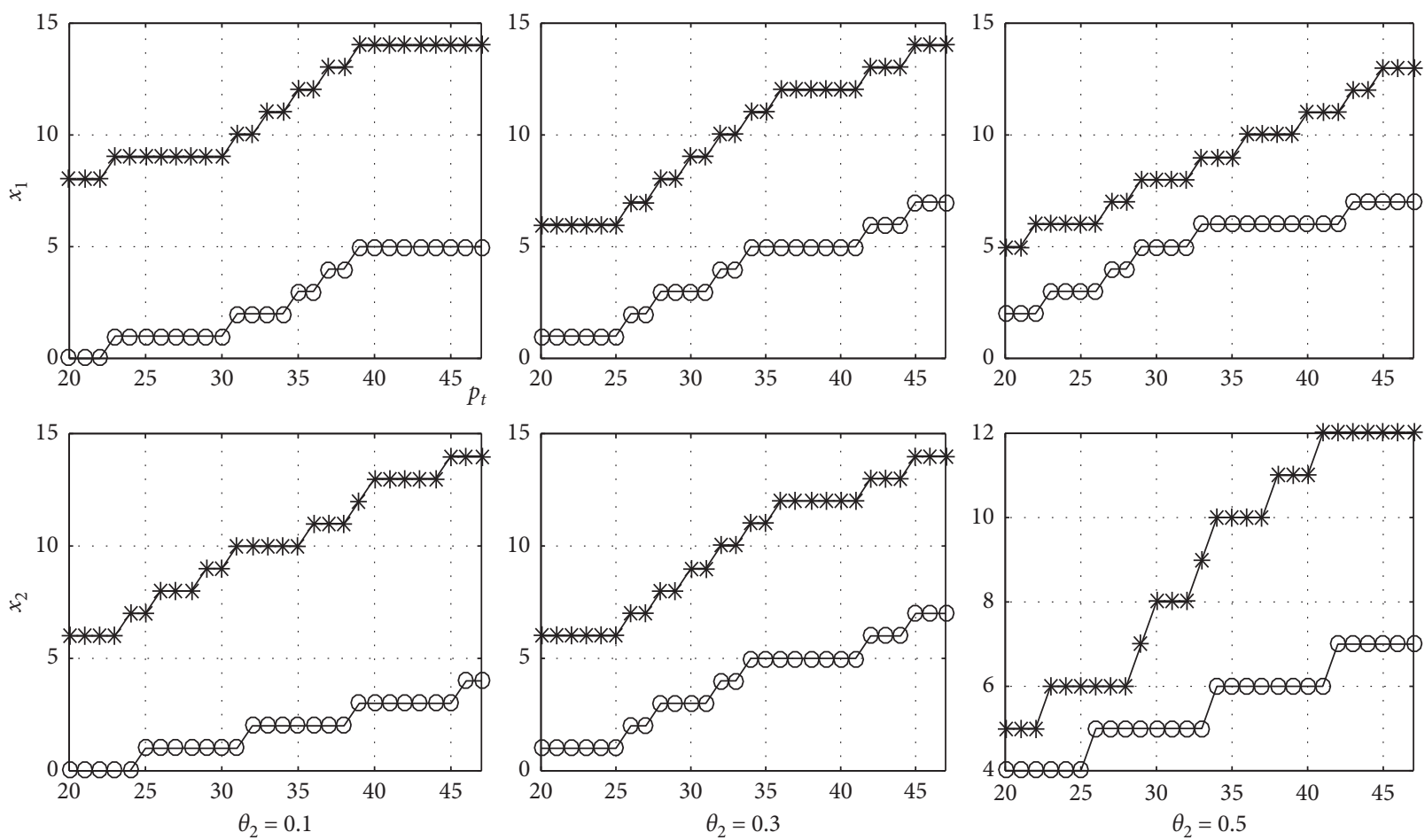

* transship-down-to level

- transship-up-to level

FIGURE 2: Relationship of the transshipment lower and upper levels with the switching rate.
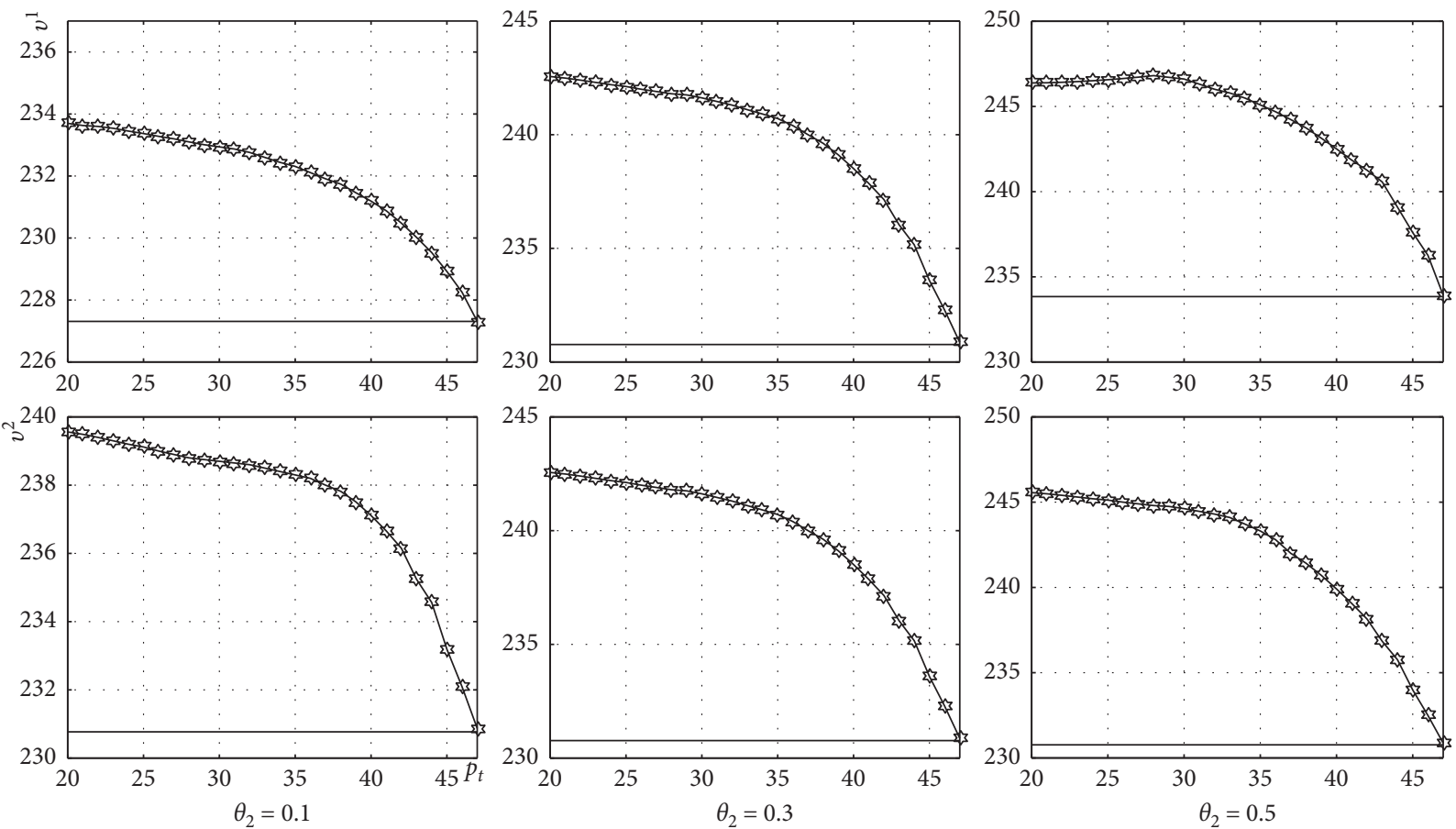

- profit without transshipment

FIGURE 3: Relationship between the profit and switching rate. 
risk from transshipment due to the strategic substitute relation. When the switching rate is a lower, retailer 2 orders fewer units to reduce the risk of an overstock, which causes retailer 1 to share less profit with her. As the switching rate increases, retailer 2 orders more and bears a higher risk of an overstock, which induces retailer 1 to share more profits. In addition, the profit of two retailers is nondecreasing in the transshipment price. The reason is that if the transshipment price is low, two retailers tend to order more, which leads to a relatively lower risk of out-of-stock. As the transshipment price increases, both retailers are reluctant to implement transshipment. Although the profit collecting from transshipment is lower, the risk of overstock is gradually reduced. Therefore, there is a higher total profit.

\section{Conclusion}

This paper has tested the relationship between hybrid transit policies and customer switching behavior in a decentralized system. It is well known that the interaction of the transshipment and customer switching behaviour will exacerbate the complexity of the structure of a hybrid transshipment policy. To cope with this problem, there is a need for the retailer to take two factors into consideration before making ordering decisions. Therefore, we develop a discrete-time dynamic programming to analyse the optimal hybrid transshipment policy and ordering policy with customer switching behaviour. The main conclusions are as follows.

(1) The implications of a hybrid transshipment policy are shown. That is, the retailer can obtain more profits with a hybrid transshipment than without one when the transshipment price within a certain range motivates two retailers to transship in or out one unit.

(2) We develop an easy-to-implement hybrid transshipment policy to control inventory regardless of the other retailer's transshipment policy as long as the inventory is observed because the optimal hybrid transshipment policy is a dominant equilibrium strategy.

(3) We explore the structural properties of two threshold functions to adjust the inventory by the inventory control-band, which consists of the thresholds of the transship upper level and transship lower level, allowing the retailer to transfer the risk of a stockout or overstock by transshipping in or out one unit in advance or after a period of time.

(4) The existence of an ordering Nash equilibrium for two retailers is obtained, which indicates that two retailers' ordering policy has a substitute relationship due to the hybrid transshipment and customer switching behaviour.

(5) The retailer is more willing to adjust the inventory by ordering when there is a lower transshipment price and to adjust the inventory by hybrid transshipment when there is a higher price. In addition, there are at most two transshipment areas for the two retailers, and the implementation of a transshipment is prevented as the switching rate increases.

It is worthwhile to note that we only consider a two retailers system. However, there are many possible avenues to extend our two-retailer model to an $\mathrm{N}$-retailer model for future research. Another interesting question is as follows: how should the transshipment price be determined? Since the transshipment depends on its price, a higher transshipment price tends to result in less transshipped inventory, while a lower transshipment price has the opposite effect. If one of the retailers sets the transshipment price, is there an optimal price between the two prices? It is also unclear how an endogenous transshipment price will affect the retailers' ordering decisions. Furthermore, is there a mechanism for effectively coordinating two retailers?

\section{Data Availability}

No data were used to support this study.

\section{Conflicts of Interest}

The authors declare that they have no conflicts of interest regarding the publication of this paper.

\section{Acknowledgments}

This research was supported by Key Laboratory of "Internet +" Collaborative Intelligent Manufacturing of Guizhou Province and in part by a research grant from the National Natural Science Foundation of China (nos. 71661004 and 72161004); Chinese Postdoctoral Science Foundation (no. 2017M 610743); Natural Science Foundation of Guizhou Province of China (no. ZK[2021]-323); Educational Commission of Guizhou Province (nos. 2018SSD05 and 2019JD004); and Chongqing Basic Research and Frontier Exploration Project of Chongqing (no. cstc2018jcyjax0793).

\section{Supplementary Materials}

Appendix. Proofs of Theorems 1, 2, 3, and 4 and Propositions 1 and 2. (Supplementary Materials)

\section{References}

[1] T. Gruen and D. Corsten, "Stock-outs cause walkouts," Harvard Business Review, vol. 82, no. 5, pp. 26-27, 2004.

[2] D. S. Wu, B. F. Zhang, and O. Baron, "A trade credit model with asymmetric competing retailers," Production and Operations Management, vol. 28, no. 4, pp. 206-231, 2019.

[3] S. Tierney, "P\&G has better news on stock-outs," Supply Chain Europe, vol. 13, no. 9, p. 28, 2004.

[4] W. Verbeke and R. Thurilk, "Consumer response to the preferred brand out-of-stock situation," European Journal of Operational Research, vol. 32, no. 3, pp. 1008-1028, 1998.

[5] F. Caro, J. Gallien, M. Díaz, and J. García, "Zara uses operations research to reengineer its global distribution process," Interfaces, vol. 40, no. 1, pp. 71-84, 2010.

[6] C. J. Guo, R. G. Thompson, G. Foliente, and X. T. R. Kong, "An auction-enabled collaborative routing mechanism for 
omnichannel on-demand logistics through transshipment," Transportation Research Part E: Logistics and Transportation Review, vol. 146, no. 1, Article ID 102206, 2021.

[7] H. Zhao, J. Ryan, and V. Deshpande, "Optimal dynamic production and inventory transshipment policies for a twolocation make-to-stock system," Operations Research, vol. 56, no. 2, pp. 400-410, 2008.

[8] D. Derhami, B. Montreuil, and G. Bau, "Assessing product availability in omnichannel retail networks in the presence of on-demand inventory transshipment and product substitution," Omega, vol. 102, no. 7, Article ID 102315, 2021.

[9] D. Gross, Centralized Inventory Control in Multilocation Supply Systems, Stanford University Press, Stanford, CA, USA, 1963.

[10] B. Hoadley and D. P. Heyman, "A two-echelon inventory model with purchases, dispositions, shipments, returns and transshipments," Naval Research Logistics Quarterly, vol. 24, no. 1, pp. 1-19, 1977.

[11] Y. Rong, L. V. Snyder, and Y. Sun, "Inventory sharing under decentralized preventive transshipments," Naval Research Logistics, vol. 57, no. 6, pp. 540-562, 2010.

[12] Y. Liao, J. Li, X. Hu, Y. Li, and W. Shen, "Application of lateral transshipment in cost reduction of decentralized systems," Sustainability, vol. 12, no. 12, pp. 5081-5101, 2020.

[13] B. Dan, Q. R. He, K. W. Zheng, and R. Liu, "Two-period ordering and pricing model of retailers' preventive transshipment dominated by producer under return constraint," Computers \& Industrial Engineering, vol. 100, no. 10, pp. 24-33, 2016.

[14] P. Feng, R. Y. K. Fung, and F. T. Jia, "Evaluation of two transshipment policies in a two-location decentralized inventory system under partial backordering," Transportation Research Part E: Logistics and Transportation Review, vol. 118, no. 10, pp. 207-224, 2018.

[15] M. Dehghani, B. Abbasi, and F. Oliveira, "Proactive transshipment in the blood supply chain: a stochastic programming approach," Omega, vol. 98, no. 1, Article ID 102112, 2021.

[16] V. Agrawal, X. Chao, and S. Seshadri, "Dynamic balancing of inventory in supply chains," European Journal of Operational Research, vol. 159, no. 2, pp. 296-317, 2004.

[17] K. Roodbergen, "Transshipment and rebalancing policies for library books," European Journal of Operational Research, vol. 228, no. 2, pp. 447-456, 2013.

[18] Z. Pang, H. Shen, and T. Cheng, "Inventory rationing in a make-to-stock system with batch production and lost sales," Production and Operations Management, vol. 23, no. 7, pp. 1243-1257, 2014.

[19] P. Feng, R. Y. K. Fung, and F. Wu, "Preventive transshipment decisions in a multi-location inventory system with dynamic approach," Computers \& Industrial Engineering, vol. 104, no. 4, pp. 1-8, 2017.

[20] A. C. C. Van Wijk, I. J. B. F. Adan, and H. G. J. Van, "Optimal lateral transshipment policies for a two location inventory problem with multiple demand classes," European Journal of Operational Research, vol. 272, no. 1, pp. 481-495, 2019.

[21] B. Feaa, B. Fra, and C. Sl, "Spare parts inventory routing problem with transshipment and substitutions under stochastic demands," Applied Mathematical Modelling, vol. 101, no. 1, pp. 309-331, 2021.

[22] C. Paterson, G. Kiesmüller, R. Teunter, and K. Glazebrook, "Inventory models with lateral transshipments: a review," European Journal of Operational Research, vol. 210, no. 2, pp. 125-136, 2011.
[23] R. Teunter, C. Paterson, and K. Glazebrook, "Hybrid lateral transshipments in a multi-location inventory system (research report)," 2010.

[24] C. Paterson, R. Teunter, and K. Glazebrook, "Enhanced lateral transshipments in a multi-location inventory system," $E u$ ropean Journal of Operational Research, vol. 221, no. 2, pp. 317-327, 2012.

[25] K. Glazebrook, C. Paterson, S. Rauscher, and T. Archibald, "Benefits of hybrid lateral transshipments in multi-item inventory systems under periodic replenishment," Production and Operations Management, vol. 24, no. 2, pp. 311-324, 2014.

[26] D. Nakandala, H. Lau, and J. Zhang, "Strategic hybrid lateral transshipment for cost-optimized inventory management," Industrial Management \& Data Systems, vol. 117, no. 8, pp. 1632-1649, 2017.

[27] X. Zhao and D. Atkins, "Transshipment between competing retailers,” IIE Transactions, vol. 41, no. 8, pp. 665-676, 2009.

[28] Y. Liao, W. Shen, X. Hu, and S. Yang, "Optimal responses to stockouts: lateral transshipment versus emergency order policies," Omega, vol. 49, no. 6, pp. 79-92, 2014.

[29] Y. Li, Y. Liao, X. X. Hu, and W. J. Shen, "Lateral transshipment with partial request and random switching," Omega, vol. 92, no. 4, pp. 102134-102148, 2020.

[30] P. Zhang, X. F. Xu, V. Shi, and J. Zhu, "Simultaneous inventory competition and transshipment between retailers," International Journal of Production Economics, vol. 230, no. 11, Article ID 107781, 2020.

[31] L. Silbermayr, "A review of non-cooperative newsvendor games with horizontal inventory interactions," Omega, vol. 92, no. 4, Article ID 102148, 2020.

[32] J. Q. Yang, X. M. Zhang, H. Y. Zhang, and C. Liu, "Cooperative inventory strategy in a dual-channel supply chain with transshipment consideration," International Journal of Simulation Modelling, vol. 15, no. 2, pp. 365-376, 2016.

[33] N. Cömez, K. E. Stecke, and M. Cakanyldlm, "In-season transshipments among competitive retailers," Manufacturing \& Service Operations Management, vol. 14, no. 2, pp. 290-300, 2012.

[34] D. D. Fan, Q. Xu, T. J. Fan, and F. Z. Cheng, "Inventory optimization model considering consumer shift and inventory transshipment in dual-channel supply chains," RAIROOperations Research, vol. 53, no. 1, pp. 59-79, 2019.

[35] S. A. Lippman, "Applying a new device in the optimization of exponential queuing systems," Operations Research, vol. 23, no. 4, pp. 687-710, 1975.

[36] N. Rudi, S. Kapur, and D. F. Pyke, "A two-location inventory model with transshipment and local decision making," Management Science, vol. 47, no. 12, pp. 1668-1680, 2001. 